\title{
Multi-Omics Reveal the Efficient Phosphate-Solubilizing Mechanism of Bacteria on Rocky Soil
}

\author{
Yanqiang Ding ${ }^{1 \dagger}$, Zhuolin $\mathrm{Yi}^{1 \dagger}$, Yang Fang ${ }^{1}$, Sulan $\mathrm{He}^{2}$, Yuming $\mathrm{Li}^{2}$, Kaize $\mathrm{He}^{1}$, Hai Zhao ${ }^{1}$ and \\ Yanling $\mathrm{Jin}^{1 *}$
}

${ }^{1}$ CAS Key Laboratory of Environmental and Applied Microbiology, Environmental Microbiology Key Laboratory of Sichuan Province, Chengdu Institute of Biology, Chinese Academy of Sciences, Chengdu, China, ${ }^{2}$ Sweetpotato Institute, Nanchong Academy of Agricultural Sciences, Nanchong, China

OPEN ACCESS

Edited by:

Om Prakash

National Centre for Cell Science,

India

Reviewed by:

Maria Carolina Quecine,

University of São Paulo, Brazil

Ewoud Ewing,

Karolinska Institutet (KI), Sweden Harold Alexander Vargas Hoyos, University of Antioquia, Colombia

Hillol Chakdar,

National Bureau of Agriculturally Important Microorganisms (ICAR),

India

*Correspondence:

Yanling Jin

jiny@@cib.ac.cn

tThese authors have contributed equally to this work

Specialty section:

This article was submitted to Evolutionary and Genomic Microbiology,

a section of the journal

Frontiers in Microbiology

Received: 20 August 2021 Accepted: 22 November 2021 Published: 09 December 2021

Citation:

Ding $Y, Y i$, Fang $Y, H e S, L i Y, H e K$, Zhao $H$ and Jin $Y$ (2021) Multi-Omics

Reveal the Efficient Phosphate-

Solubilizing Mechanism of Bacteria on Rocky Soil.

Front. Microbiol. 12:761972.

doi: 10.3389/fmicb.2021.761972
Phosphate-solubilizing bacteria (PSB) can alleviate available phosphorus (AP)-deficiency without causing environmental pollution like chemical phosphate fertilizers. However, the research and application of PSB on the barren rocky soil is very rare. We screened six PSB from sweetpotato rhizosphere rocky soil. Among them, Ochrobactrum haematophilum FP12 showed the highest P-solubilizing ability of $1,085.00 \mathrm{mg} / \mathrm{L}$ at 7 days, which was higher than that of the most reported PSB. The assembled genome of PSB FP12 was 4.92 $\mathrm{Mb}$ with P-solubilizing and plant growth-promoting genes. In an AP-deficient environment, according to transcriptome and metabolomics analysis, PSB FP12 upregulated genes involved in gluconic acid synthesis and the tricarboxylic acid cycle, and increased the concentration of gluconic acid and malic acid, which would result in the enhanced P-solubilizing ability. Moreover, a series of experiments in the laboratory and field confirmed the efficient role of the screened PSB on significantly increasing AP in the barren rocky soil and promoting sweetpotato yield. So, in this study, we screened highly efficient PSB, especially suitable for the barren rocky soil, and explored the P-solubilizing mechanism. The research will reduce the demand for chemical phosphate fertilizers and promote the environment-friendly agricultural development.

Keywords: barren rocky soil, application potential, multi-omics, phosphate-solubilizing bacteria, phosphate-solubilizing mechanism

\section{INTRODUCTION}

Available phosphorus (AP) is deficient in $74 \%$ of the arable soil of China and in more than $40 \%$ of the arable soil globally, because about $99 \%$ of the total phosphorus (TP) is dissolved (Balemi and Negisho, 2012; Yu et al., 2019). This leads to a huge demand for chemical phosphate fertilizers. According to the report of the Food and Agriculture Organization of the United Nations, the world's demand for phosphate fertilizer has reached 45.86 million tons in $2020 .{ }^{1}$ However, the utilization rate of chemical phosphate fertilizers is as low as $10-25 \%$ (Roberts and Johnston, 2015). Moreover, excessive chemical phosphate fertilizer would result in soil nutrition imbalance, heavy metal accumulation, and water eutrophication, meanwhile the production of chemical phosphate fertilizer often causes some other environmental pollution (Huang et al., 2017;

${ }^{1}$ http://www.fao.org/ 
Park et al., 2021). Therefore, developing methods to reduce the demand for chemical phosphate fertilizers and improve the bioavailability of soil TP is of significance to both agricultural production and environmental protection.

Microorganisms play an important role in the biogeochemical cycle. Among them, phosphate-solubilizing bacteria (PSB) can degrade insoluble inorganic and organic phosphorus into AP, which would then be easily absorbed and utilizated by plants (Granada et al., 2018; Wei et al., 2018; Parastesh et al., 2019; Bi et al., 2020). The previous researches screened out some PSB, which showed good P-solubilizing ability $(115-716 \mathrm{mg} / \mathrm{L})$ under laboratory culture conditions (Yu et al., 2019; Kaur and Kaur, 2020). However, it was reported that, in about $70 \%$ of the experiments, PSB did not play a direct role in supplementing soil AP for plants (Gyaneshwar et al., 2002). Considering possible effects of the different organic matter, $\mathrm{pH}$, and other characteristics of the soil on the colonization and function of PSB, it is very necessary to develop suitable PSB for different types of soil.

Sedimentary rock covers $75-80 \%$ of the Earth's crust, forming parent materials for a large majority of soils (Wilkinson et al., 2009). In the Sichuan Basin, China, more than $70 \%$ of the hills (approximately $5.0 \times 10^{10} \mathrm{~m}^{2}$ ) are covered by barren rocky soil, a kind of weathered shale. Rocky soil has high potential for agricultural utilization (Manning and Theodoro, 2018). However, the AP in the rocky soil is very deficient, moreover, in which chemical phosphate fertilizer is more easily washed away and cause serious environmental pollution (Huang et al., 2017). There have been some PSB fertilizers for arable soil, but there are few studies on PSB suitable for the barren rocky soil.

The unclear mechanism of PSB is one of the important factors blocking the application of PSB (Elhaissoufi et al., 2021). Normally, direct oxidation of glucose to gluconic acid is thought to be the main P-solubilizing way in Gram-negative bacteria (Sashidhar and Podile, 2010; Luduena et al., 2018). Whereas, other studies found that pyruvate, lactic acid, succinic acid, and citric acid were the main organic acids secreted by PSB when solubilizing P (Li et al., 2017; Zeng et al., 2017). Furthermore, there is controversy regarding the effect of $\mathrm{P}$ availability on the $\mathrm{P}$-solubilizing ability of PSB (Zeng et al., 2017). In addition, there is few systematic study on how PSB respond to P-deficiency and synthesize and secrete organic acids (Zeng et al., 2017). Fortunately, genomics, transcriptome, metabolomics, and other omics technologies have recently provided powerful methods to shed light on the P-solubilizing mechanism and application research.

The main objectives of this study were: (i) to screen highly efficient PSB suitable for the barren rocky soil, (ii) to explore the P-solubilizing mechanism at the level of genome, transcriptome, and metabolomics, and (iii) to verify the application effect of the PSB on the barren rocky soil.

\section{MATERIALS AND METHODS}

\section{Screening for PSB}

Sweetpotato rhizosphere rocky soil samples were collected at the Yingxi experimental base of the Nanchong Academy of Agricultural Sciences, Sichuan, China $\left(30^{\circ} 52^{\prime} \mathrm{N}, 106^{\circ} 02^{\prime} \mathrm{E}\right)$ using the methods described in a previous study (Ding et al., 2020). The soil type is purplish soils according to classification and codes for Chinese soil (GB/T 17296-2009). Soil samples (2.0 g) and sterile water $(30 \mathrm{ml})$ were mixed to obtain a bacterial suspension. Bacterial strains were cultured and purified on Luria-Bertani medium according to the dilution coating method and streak plate method (Sanders, 2012).

The purified strains were inoculated on modified PKOC2 medium with sterilized toothpicks (Li et al., 2019), and the plates were inverted and incubated in a $28^{\circ} \mathrm{C}$ incubator. The strains with P-solubilizing circles were selected for re-screening. Holes with a diameter of $6.00 \mathrm{~mm}$ were punched in the screening medium. Next, $100 \mu \mathrm{l}$ of the cultured bacterial solution with the same $\mathrm{OD}_{600}$ value were inoculated into the holes. After 7 days of incubation in a $28^{\circ} \mathrm{C}$ incubator, the diameter of the P-solubilizing circle was measured.

About $2 \mathrm{~mm}$ of cultured bacterial solution with the same $\mathrm{OD}_{600}$ value were inoculated into a $100 \mathrm{ml}$ triangle flask containing $30 \mathrm{ml}$ of Monkina inorganic P culture medium (Yh, 2014), with three replicates per strain. After incubation at $28^{\circ} \mathrm{C}$ and $150 \mathrm{rpm}$ in a shaking incubator for 7 days, the $\mathrm{pH}$ of the medium was determined using a $\mathrm{pH}$ meter (PHS-3C, Fangzhou, China), and the AP of the medium was determined using the molybdenum blue method (Murphy and Riley, 1962).

\section{Identification of PSB}

For six strains of PSB (BP10, BP11, BP23, FP2, FP12, and FP16), $2 \mathrm{ml}$ of the bacterial solution were used for $16 \mathrm{~S}$ rRNA gene sequencing. The genomic DNA were extracted using the SDS method (Natarajan et al., 2016). The amplified 16S rRNA genes were obtained with specific primers (27F: 5'-AGTTTGATCMTGGCTCAG-3'; 1492R: 5'-GGTTACCTT GTTACGACTT-3'), and sequenced using the Sanger sequencing platform (Chen et al., 2015). The 16S rRNA gene sequences were aligned to the $\mathrm{NCBI}^{2}$ database to search for the species with the highest similarity, wherein the selection " $16 \mathrm{~S}$ ribosomal RNA (Bacteria and Archaea)" was made. The EZBioCloud platform was further used for strain identification (Yoon et al., 2017a).

\section{Phosphate-Solubilizing Profile of PSB}

To explore the P-solubilizing mechanism, PSB FP12, the efficient PSB selected from this study, was cultured in four kinds of media with different $\mathrm{P}$ sources. Four media were used as PKOC2 medium [the insoluble $\mathrm{P}$ medium (IPM)], PKOC2 medium with the replace of $\mathrm{Ca}_{3}\left(\mathrm{PO}_{4}\right)_{2}$ with $3.02 \mathrm{~g} \mathrm{NaH}_{2} \mathrm{PO}_{4} \cdot 2 \mathrm{H}_{2} \mathrm{O}$ [the available $\mathrm{P}$ medium (APM)], PKOC2 medium with the addition of $3.02 \mathrm{~g} \mathrm{NaH}_{2} \mathrm{PO}_{4} \cdot 2 \mathrm{H}_{2} \mathrm{O}$ [the insoluble and available $\mathrm{P}$ medium (IAPM)], and the PKOC2 medium without $\mathrm{Ca}_{3}\left(\mathrm{PO}_{4}\right)_{2}$ [no P medium (NPM)]. Each group had three replicates. After incubation at $28^{\circ} \mathrm{C}$ and $150 \mathrm{rpm}$ in a shaking incubator for 7 days, the $\mathrm{pH}$ and $\mathrm{AP}$ of the medium were similarly determined as above.

${ }^{2}$ https://blast.ncbi.nlm.nih.gov/ 


\section{Organic Acids Targeted Metabolomics}

At 1 and 2 days, as the $\mathrm{pH}$ and dissolved $\mathrm{P}$ changed largely, the solution from groups IPM and APM were sampled and filtered through a $0.2 \mu \mathrm{m}$ filter membrane for organic acidtargeted metabolomics analysis. Each group had three replicates. The following organic acids were measured, i.e., gluconic acid, 2 -keto-gluconic acid, malic acid, acetic acid, $\alpha$-ketoglutaric acid, lactic acid, formic acid, citric acid, succinic acid, pyruvate, oxalic acid, and tartaric acid.

The organic acid-targeted metabolomics was performed using an Agilent liquid chromatograph (Aglient1200, United States). The liquid chromatograph column was the LAEQ-462572 Athena C18-WP $4.6 * 250 \mathrm{~mm}$, with a column temperature of $30^{\circ} \mathrm{C}$ (van Hees et al., 1999). The detection wavelength was $210 \mathrm{~nm}$ (Zitouni et al., 2020). Chromatographic standard samples were used to draw standard curves to ensure that $R^{2}>0.99$.

\section{Genome Sequencing of PSB FP12}

The genomic DNA of PSB FP12 was extracted using the SDS method (Natarajan et al., 2016). Then the high-quality genomic DNA was sequenced using the Illumina NovaSeq sequencing platform (Illumnia, Inc., San Diego, CA, PE150). The raw sequencing data was filtered using Readfq (Version 10) ${ }^{3}$ with default parameters. The filtered clean data was analysed for PSB FP12 genome de novo assembly using SOAPdenovo (Version 2.04) with default parameters (Luo et al., 2012). Then GapCloser (Version 1.12) ${ }^{4}$ was used to fill gaps in the initial assembly genome. And the short contigs below $500 \mathrm{bp}$ were filtered out.

GeneMarkS (Version 4.17) was used to predict the coding genes of the genome (Besemer et al., 2001). Diamond was used to align the predicted protein sequence with GO, KEGG, COG, NR, Pfam, TCDB, and Swiss-Prot (e-value $\leq 1 \mathrm{e}-5$; Buchfink et al., 2015). For the alignment of each protein sequence, the match with the highest score (default identity $\geq 40 \%$, coverage $\geq 40 \%$ ) was used to select the functional annotation. A map of the circular genome was drawn with BRIG (Version 0.95; Alikhan et al., 2011). The Average Nucleotide Identity (ANI) of the genome of PSB FP12 and related species was calculated using the ANI Calculator (Yoon et al., 2017b).

\section{Transcriptome of PSB FP12}

In order to study the transcriptional expression changes of PSB FP12 in a P-deficient environment, we analyzed the transcriptome of PSB FP12 in the insoluble P medium (IPM group) and the available $\mathrm{P}$ medium (APM group). At 1 and 2 days, the solution from groups IPM and APM were sampled, and each group was sampled in triplicate. The RNA of PSB FP12 was extracted using the TRIZOL method (Rio et al., 2010). Qualified libraries were sequenced on the Illumina Novaseq sequencing platform using the paired-end sequencing method (PE150). FastQC_v0.11.3 was used for quality control of the raw sequencing data. The filtered sequence was aligned with the rRNA database using Bowtie2 to remove the rRNA sequence (Langmead and Salzberg, 2012).

Qualified sequencing data were aligned to the PSB FP12 genome using Hisat2 (Kim et al., 2015), and the count value and the Reads Per Kilobase per Million mapped reads (RPKM) values of the genes were calculated using HTseq-count and AWK script (Anders et al., 2015). EdgeR was used to calculate the differentially expressed genes $\left[p<0.05\right.$ and $\mid \log _{2}$ (fold change) $\mid>1$; Robinson et al., 2009]. Gene Ontology (GO) classification and enrichment analysis of differentially expressed genes was performed on the WEGO 2.0 platform (Ye et al., 2018). KEGG enrichment analysis of differentially expressed genes was performed based on the KEGG database. ${ }^{5}$

\section{Treating the Barren Rocky Soil With PSB}

To verify the application effects of those selected PSB on the barren rocky soil, a series of experiments were performed. The barren rocky soil was collected at the Yingxi, Nanchong, Sichuan, China $\left(30^{\circ} 52^{\prime} \mathrm{N}, 106^{\circ} 02^{\prime} \mathrm{E}\right)$. The soil type is purplish soils according to Classification and codes for Chinese soil (GB/T 17296-2009; Supplementary Figure S1). The barren rocky soil properties were showed in Supplementary Table S1. About $1 \mathrm{ml}$ of single PSB (BP10, BP11, BP23, FP2, FP12, or FP16; approximately $10^{9} \mathrm{CFU} / \mathrm{ml}$ ) or the mixed PSB (MB group) were added to $10 \mathrm{~g}$ of sterilized barren rocky soil. Around $1 \mathrm{ml}$ sterile water without PSB was added in the control (CK) group. After 10 days of incubation in a $28^{\circ} \mathrm{C}$ incubator, the soil $\mathrm{pH}$ and $\mathrm{AP}$ were measured using the methods described in a previous study (Ding et al., 2020).

\section{Addition of Sweetpotato Root Exudates}

One of the main factors limiting the colonization of PSB in the barren rocky soil is the lack of organic matter. Plant root exudates are important sources of soil organic matter, and plants can affect the colonization of rhizosphere microorganisms through root exudates (Sasse et al., 2018). Therefore, the effect of plant root exudates was also considered when developing PSB suitable for the barren rocky soil.

Sweetpotato root exudates were collected according to methods described previously (Ding et al., 2020). BP10, BP11, BP23, FP2, FP12, and FP16 PSB (approximately $10^{\circ} \mathrm{CFU} / \mathrm{ml}$ ) were mixed in equal proportions and then centrifuged. The supernatant was discarded, and the remaining pellet was resuspended in sterile water. Around $10 \mathrm{ml}$ of the resuspended PSB was added to $100 \mathrm{~g}$ of sterilized barren rocky soil, then $10 \mathrm{ml}$ of sweetpotato root exudates was added as a treatment group (BR group), and $10 \mathrm{ml}$ of sterile water was added as a control group (BW group). Meanwhile, $20 \mathrm{ml}$ of sterile water was added to $100 \mathrm{~g}$ of sterilized soil, without PSB, as another control (BCK group). After 10 days of incubation in a $28^{\circ} \mathrm{C}$ incubator, the soil $\mathrm{pH}$ and AP were measured using the methods described in a previous study (Ding et al., 2020). 


\section{Pot Experiments}

A greenhouse pot experiment was performed in a greenhouse $\left(30^{\circ} 63^{\prime} \mathrm{N}, 104^{\circ} 07^{\prime} \mathrm{E}\right)$ at Chengdu Institute of Biology, Chinese Academy of Sciences. A strain of sweetpotato [Ipomoea batatas (L.) Lam.] cultivar Nanshu 88 was planted in a pot (high, $26.5 \mathrm{~cm}$; diameter $24.0 \mathrm{~cm}$ ) containing $6.5 \mathrm{~kg}$ of barren rocky soil. In the BP group, $75 \mathrm{ml}$ of mixed PSB (approximately $10^{9} \mathrm{CFU} / \mathrm{ml}$ ) was applied to each pot; in the $\mathrm{CK}$ group, $75 \mathrm{ml}$ of sterile water without PSB was applied. Each group had eight pots. The greenhouse temperature was $25^{\circ} \mathrm{C}$.

The field pot experiment was performed at the Yingxi experimental base $\left(30^{\circ} 52^{\prime} \mathrm{N}, 106^{\circ} 02^{\prime} \mathrm{E}\right)$, and designed same as in the greenhouse pot experiment. During the experiment, the local monthly precipitation was $64-180 \mathrm{~mm}$, and the mean temperature was $18.5-28.4^{\circ} \mathrm{C}$.

At 100 days, the sweetpotato and soil in the greenhouse and field pot experiments were weighed and sampled. The $\mathrm{P}$ and potassium $(\mathrm{K})$ content of sweetpotato roots and vines were measured using an elemental content analyzer with inductively coupled plasma optical emission spectrometry (ICPOES; Optima 8300, PerkinElmer, United States). The nitrogen (N) content of sweetpotato roots and vines, as well as the $\mathrm{pH}$, total carbon (TC), total nitrogen (TN), and AP of soil were measured using the methods described in a previous study (Ding et al., 2020).

\section{Statistics Analysis}

Significant differences between samples were evaluated using Tukey's honest significant difference test on R (version 3.5.0). Spearman's correlation coefficients between $\mathrm{AP}$ and $\mathrm{pH}$ were also calculated using $\mathrm{R}$ (version 3.5.0).

\section{RESULTS}

\section{Screening and Identification of PSB}

After preliminary screening, 26 bacterial strains that grew well on the screening media and had obvious P-solubilizing circles were selected for re-screening. These 26 PSB strains were inoculated into the round holes of the screening media to observe the P-solubilizing circle (Supplementary Figure S2A). At 7 days, the P-solubilizing circle of BP11 was the largest one, with a diameter of $25.75 \mathrm{~mm}$, and the ratio of the P-solubilizing circle to the diameter of the round hole $(\mathrm{D} / \mathrm{d})$ was 4.29. In addition, the P-solubilizing circle of PSB FP12 was also observed with a large diameter of $23.75 \mathrm{~mm}$ and $\mathrm{D} / \mathrm{d}$ of 3.96 (Supplementary Table S2).

These 26 PSB strains were inoculated and screened in the liquid media, and the AP content was measured at 7 days (Supplementary Figure S2B). Most strains showed significantly higher values of AP than the control group. The AP of FP12 reached $744.00 \mathrm{mg} / \mathrm{L}$ at 7 days, which was significantly higher than that of other strains $(p<0.001$; Supplementary Figure S2B; Supplementary Table S3) and was further optimized to $1,085.00 \mathrm{mg} / \mathrm{L}$ (Figure 1).
Combined with the re-screening results of the P-solubilizing ability on plate and shake flask, we finally selected BP10, BP11, BP23, FP2, FP12, and FP16 for further analysis. Through $16 \mathrm{~S}$ rRNA sequencing, PSB BP10, BP11, BP23, FP2, FP12, and FP16 were identified as Stenotrophomonas maltophilia, Achromobacter xylosoxidans, Achromobacter xylosoxidans, Stenotrophomonas maltophilia, Ochrobactrum haematophilum, and Cellulosimicrobium cellulans, respectively (Supplementary Table S4).

\section{The Relationship Between pH and Solubilized AP}

To study whether the P-solubilizing mechanism is related to acid production, the relationship between solubilized AP and $\mathrm{pH}$ was analyzed. The correlation analysis showed that there was a significant negative correlation between the solubilized AP and pH; Spearman $\rho$ was $-0.92(p<2.2 e-16)$. The trend analysis showed that the solubilized $\mathrm{AP}$ and $\mathrm{pH}$ correlated well in line with the logarithmic function: $\mathrm{pH}=-0.565 \mathrm{ln}$ (AP) + 7.7973, $R^{2}=0.8801$.

As shown in Figure 1A, PSB FP12 decreased the $\mathrm{pH}$ of the NPM and IPM groups rapidly, which was significantly lower than that of the APM group. This result indicated that the AP-deficient environment could enhance the acidification of PSB FP12, so as to decrease the $\mathrm{pH}$ of the medium. We also found that the $\mathrm{pH}$ of the IAPM and APM group media were significantly higher than those of the IPM and NPM group media (Figure 1A), indicating that AP might weaken the acidification of PSB FP12.

Along with the decrease of $\mathrm{pH}, \mathrm{PSB}$ FP12 rapidly increased AP in the IPM group. The AP of the IPM group significantly increased to $216.50 \mathrm{mg} / \mathrm{L}$ at 1 days, $838.33 \mathrm{mg} / \mathrm{L}$ at 2 days, and $1,085.00 \mathrm{mg} / \mathrm{L}$ at 7 days, respectively. The AP of the IPM group was always significantly higher than that of the IPCK group (Figure 1B).

\section{Organic Acid-Targeted Metabolomics of PSB FP12}

The organic acid concentrations of the IPM and APM groups at 1 and 2 days were measured. Gluconic acid, malic acid, acetic acid, $\alpha$-ketoglutaric acid, lactic acid, formic acid, citric acid, and succinic acid were detected, while pyruvate, oxalic acid, tartaric acid, and 2-keto-gluconic acid were not detected. Among them, gluconic acid showed the highest content, followed by malic acid, acetic acid, and $\alpha$-ketoglutaric acid (Figure 2).

The concentrations of organic acids in the IPM group were generally higher than these in the APM group. The concentrations of gluconic acid in the IPM group were 5,302.04 and 7,263.62 $\mu \mathrm{g} /$ $\mathrm{ml}$ at 1 and 2 days, respectively, which were significantly higher than these $(2,992.47 \mu \mathrm{g} / \mathrm{ml}$ at 1 days, $5,642.76 \mu \mathrm{g} / \mathrm{ml}$ at 2 days $)$ in the APM group. The concentrations of malic acid in the IPM group were $2,671.39$ and $3,556.95 \mu \mathrm{g} / \mathrm{ml}$ at 1 and 2 days, respectively, which were significantly higher than these $(1,791.03 \mu \mathrm{g} / \mathrm{ml}$ at 1 days, $1,778.81 \mu \mathrm{g} / \mathrm{ml}$ at 2 days $)$ in the APM group. The concentrations of acetic acid and lactic acid in the IPM group were also significantly higher than these in the APM group (Figure 2). 

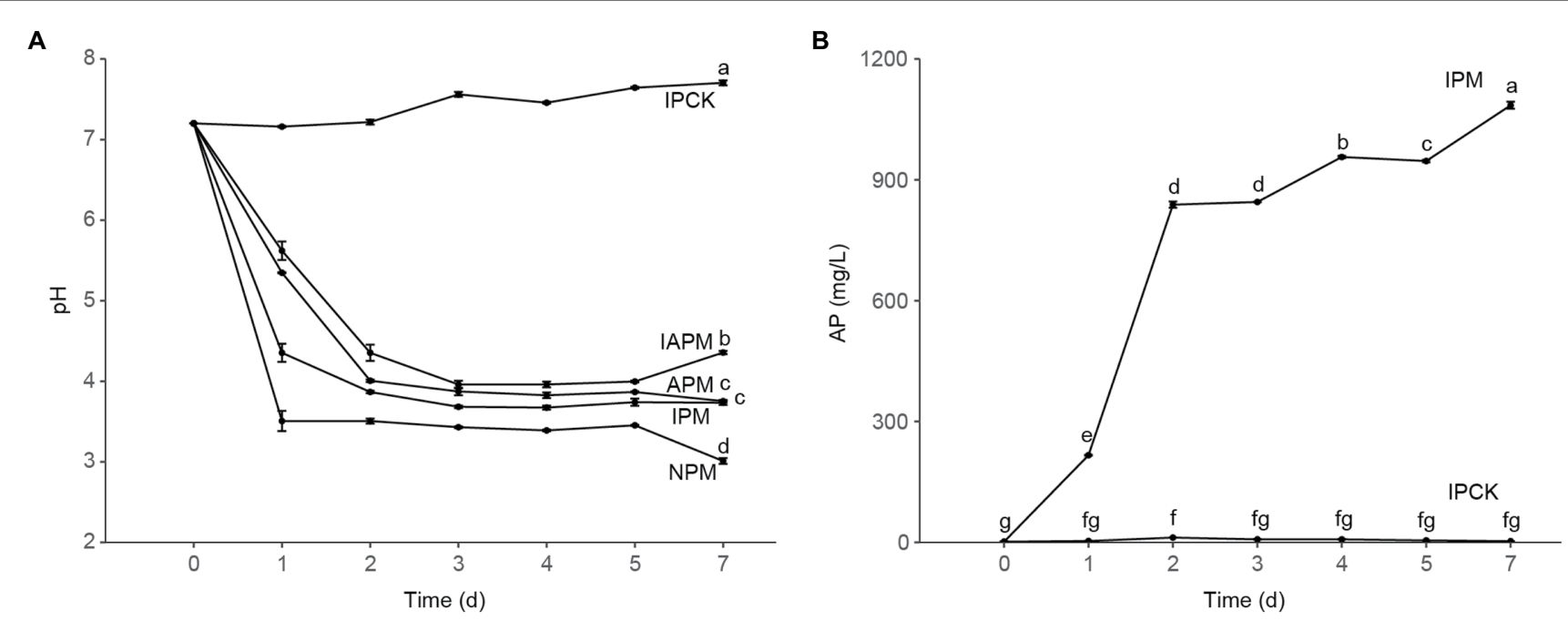

FIGURE 1 | The $\mathrm{pH}$ and solubilized available phosphorus (AP). (A) The change of pH in mediums with different phosphorus sources. Phosphate-solubilizing bacteria (PSB) FP12 was cultured in four kinds of media, i.e., insoluble phosphorus medium (IPM); available phosphorus medium (APM); insoluble and available phosphorus medium (IAPM); medium without phosphorus (NPM). IPCK is insoluble phosphorus medium without PSB. (B) The AP dissolved by phosphatesolubilizing bacteria FP12 in IPM group. Different letters denote significant difference from a Tukey's HSD test $(p<0.05)$.

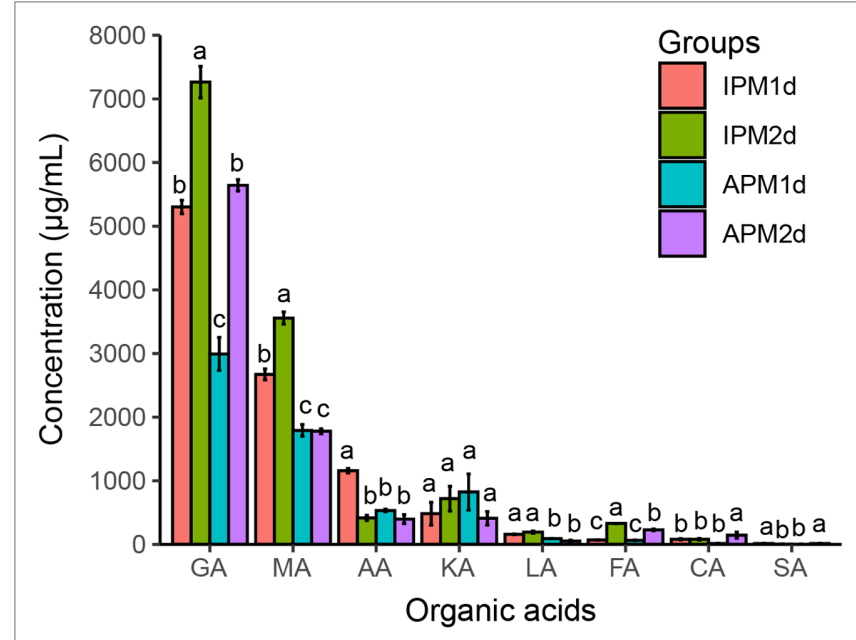

FIGURE 2 | The concentration of organic acids in IPM and APM groups. IPM1d and IPM2d represent 1 day and 2 days after inoculation of phosphatesolubilizing bacteria FP12 in the insoluble phosphorus medium, respectively. APM 1d and APM 2d represent 1 day and 2 days after inoculation of phosphate-solubilizing bacteria FP12 in the available phosphorus medium, respectively. GA, gluconic acid; $M A$, malic acid; $A A$, acetic acid; KA, $\alpha$-ketoglutaric acid; LA, lactic acid; FA, formic acid; CA, citric acid; and SA, succinic acid. Different letters denote significant difference from a Tukey's HSD test $(p<0.05)$.

\section{Genome of PSB FP12}

The final assembled genome size was $4.92 \mathrm{Mb}$ with a scaffold $\mathrm{N} 50$ of $0.32 \mathrm{Mb}$, and a GC content of $57.05 \%$. Total 4,714 genes were predicted in the PSB FP12 genome, with a total length of $4.27 \mathrm{Mb}$, accounting for $86.92 \%$ of the genome (Figure 3). While compared with the published genomes, PSB FP12 genome showed the highest ANI of $97.84 \%$ with the O. haematophilum strain
FI1154 genome (Supplementary Table S5), which indicated that they are same species.

In the PSB FP12 genome, genes for the main enzymes and their coenzymes involved in gluconic acid and 2-keto-gluconic acid synthesis were found to be: glucose dehydrogenase (GDH) gene gdhB (Quinoprotein glucose dehydrogenase, FP12_ GM000535), pyrroloquinoline quinone (PQQ) synthesis protein series genes pqqA-E (FP12_GM003319, FP12_GM003320, FP12_GM003321, FP12_GM003322, and FP12_GM003323), and gluconate dehydrogenase gene $k d u D$ (FP12_GM002270; Figure 3).

In addition, the indole acetic acid (IAA) synthetic gene [aldehyde dehydrogenase $(A L D H)$ ] and siderophores biosynthesis genes were also identified in the PSB FP12 genome.

\section{Transcriptome of PSB FP12}

The GO enrichment results showed that the differentially expressed genes between the IPM and APM groups may be related to the response of the PSB to the AP-deficient environment, the regulation of their own metabolism, and the synthesis and secretion of organic acids (Supplementary Figures S3, S4). KEGG enrichment results showed that the gene expression of the organic acid synthesis pathways, such as the gluconic acid synthesis pathway, the TCA cycle, and the pyruvate metabolic pathway, were upregulated in the AP-deficient environment (Figure 4; Supplementary Table S6).

In our study, the expression of the GDH gene $g d h B$ was significantly higher than that in the APM group at 1 days $(p<0.0001)$, and the expression levels of the PQQ synthesis protein genes, i.e., $p q q B, p q q C, p q q D$, and $p q q E$ in the IP group were higher than those in the APM group (Figure 4).

Transcriptome analysis revealed that the expression of genes related to the TCA cycle in the IPM group was generally 


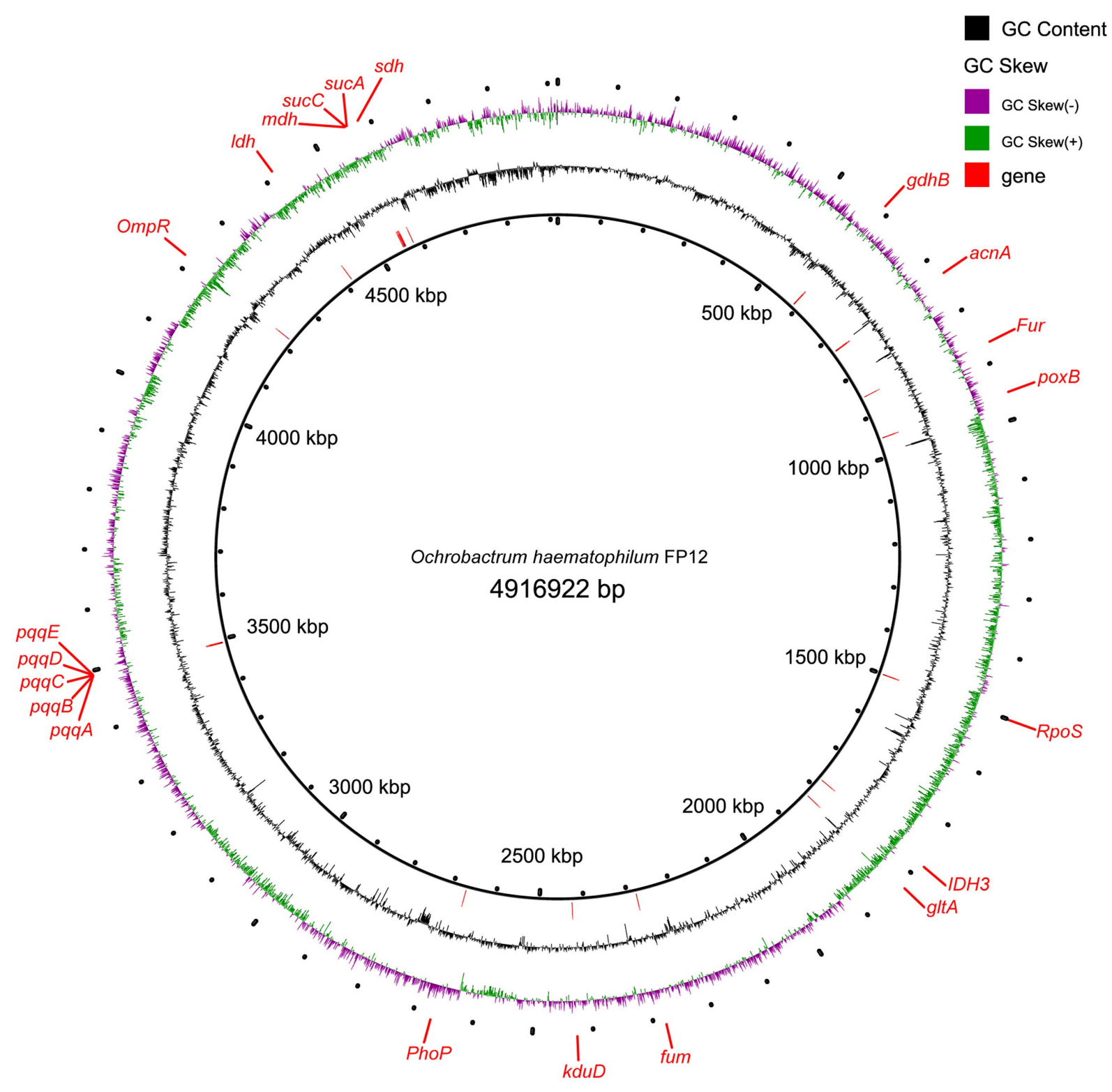

FIGURE 3 | The genome of Ochrobactrum haematophilum FP12 and genes related to phosphate-solubilizing.

higher than those in the APM group, such as citrate synthase (CS), aconitic hydratase (ACO), isocitrate dehydrogenase (IDH), $\alpha$-ketoglutarate dehydrogenase (OGDH), succinyl-CoA synthetase (SUC), succinate dehydrogenase (SDH), and fumarate hydratase (FH) genes (Figure 4). However, the expression level of the malate dehydrogenase (MDH) gene, $m d h$, in the IPM group was 671.88 RPKM at 1 days, which was lower than that (1088.42 RPKM) in the APM group, and this gene also showed lower expression levels in the IPM group (217.49 RPKM) than in the APM group (309.99 RPKM) at 2 days (Figure 4).

The expression of pyruvate dehydrogenase (POX) gene in the IPM group was significantly higher than that in the APM group $(p<0.01 ;$ Figure 4$)$. The expression of the L-lactate dehydrogenase (LDH) gene in the IPM group was significantly higher than that in the APM group ( $p<0.01$; Figure 4).

Bacteria induce an acid tolerance response by producing acid shock proteins and changing cell membrane fluidity. We found that the expression levels of these regulatory proteins in the IPM group were higher than those in the APM group (Figure 4). The expression levels of RpoS in IPM1d and IPM2d were 2682.65 RPKM and 5549.95 RPKM, respectively, which were significantly higher than those in APM group (1371.87 RPKM and 3997.41 RPKM; $p<0.01)$. The expression level of OmpR in IPM1d was 584.40 RPKM, which was higher than APM1d (556.62 RPKM); and the expression level of OmpR in IPM2d was 414.22 RPKM, which was significantly higher than that of APM1d (223.08 RPKM; $p<0.05$; Figure 4). 


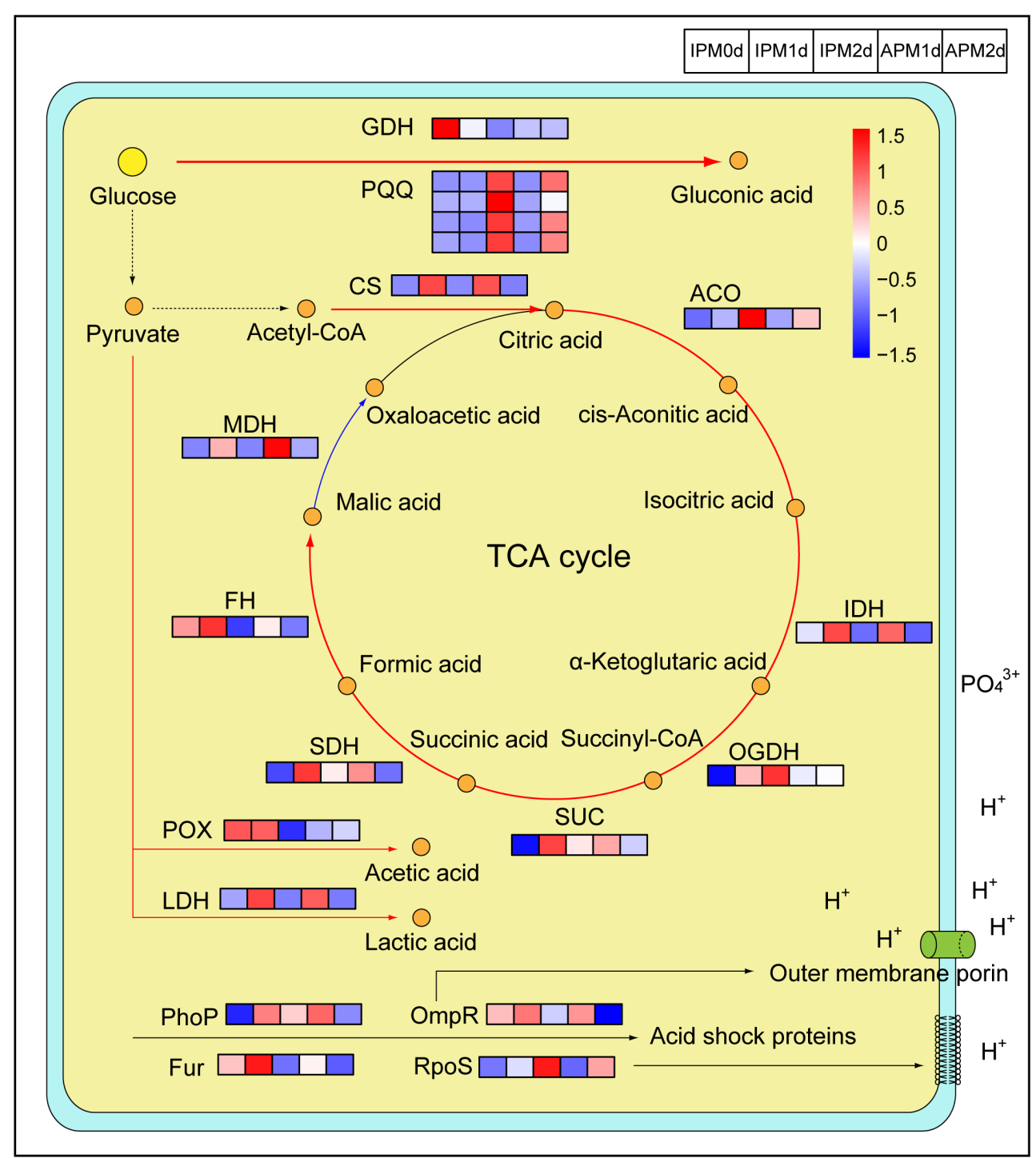

FIGURE 4 | The expression level of genes related to organic acids metabolism and acid tolerance. IPMOd, IPM1d and IPM2d represent 0 day, 1 day, and 2 days after inoculation of phosphate-solubilizing bacteria FP12 in the insoluble phosphorus medium, respectively. APM 1d and APM $2 \mathrm{~d}$ represent 1 day and 2 days after inoculation of phosphate-solubilizing bacteria FP12 in the available phosphorus medium, respectively. Red represents high expression, and blue represents low expression. GDH, glucose dehydrogenase; PQQ, pyrroloquinoline quinone; CS, citrate synthase; ACO, aconitic hydratase; IDH, isocitrate dehydrogenase; $\mathrm{OGDH}, \alpha$-ketoglutarate dehydrogenase; SUC, succinyl-COA synthetase; SDH, succinate dehydrogenase; FH, fumarate hydratase; MDH, malate dehydrogenase; POX, pyruvate dehydrogenase; and LDH, L-lactate dehydrogenase.

\section{Treating Barren Rocky Soil With PSB}

The six strains of PSB and mixed PSB significantly increased the AP in the barren rocky soil and their AP contents were significantly higher than those in the control group (Figure 5A). Among them, PSB FP12 showed the highest P-solubilizing efficiency, which significantly increased the soil AP from 1.07 to $3.08 \mathrm{mg} / \mathrm{kg}$. The mixed PSB also significantly increased the soil AP to $2.76 \mathrm{mg} / \mathrm{kg}$ (Figure 5A). Meanwhile, we found that PSB treatment significantly reduced soil $\mathrm{pH}$. The $\mathrm{pH}$ of $\mathrm{BP} 10$, BP11, BP23, FP2, FP12, FP16, and the mixed PSB groups significantly reduced from 8.54 to $8.17,8.10,8.19,8.06,8.17$, 8.16 , and 8.13 , respectively.

\section{Effects of Sweetpotato Root Exudates on P Solubilization}

The addition of sweetpotato root exudates significantly improved the P-solubilizing effect of the PSB (Figure 5B). The AP in the BR group increased from 1.07 to $2.45 \mathrm{mg} /$ $\mathrm{kg}$, which was significantly higher than that $(2.10 \mathrm{mg} / \mathrm{kg})$ in the $\mathrm{BW}$ group. The $\mathrm{AP}$ in the $\mathrm{BR}$ and $\mathrm{BW}$ groups was significantly higher than that in the BCK group $(1.26 \mathrm{mg} /$ $\mathrm{kg}$; Figure 5B). Meanwhile, we found that the $\mathrm{pH}$ of barren rocky soil in the BR group decreased significantly from 8.54 to 8.35 , which was significantly lower than that in the BW group (8.56). 

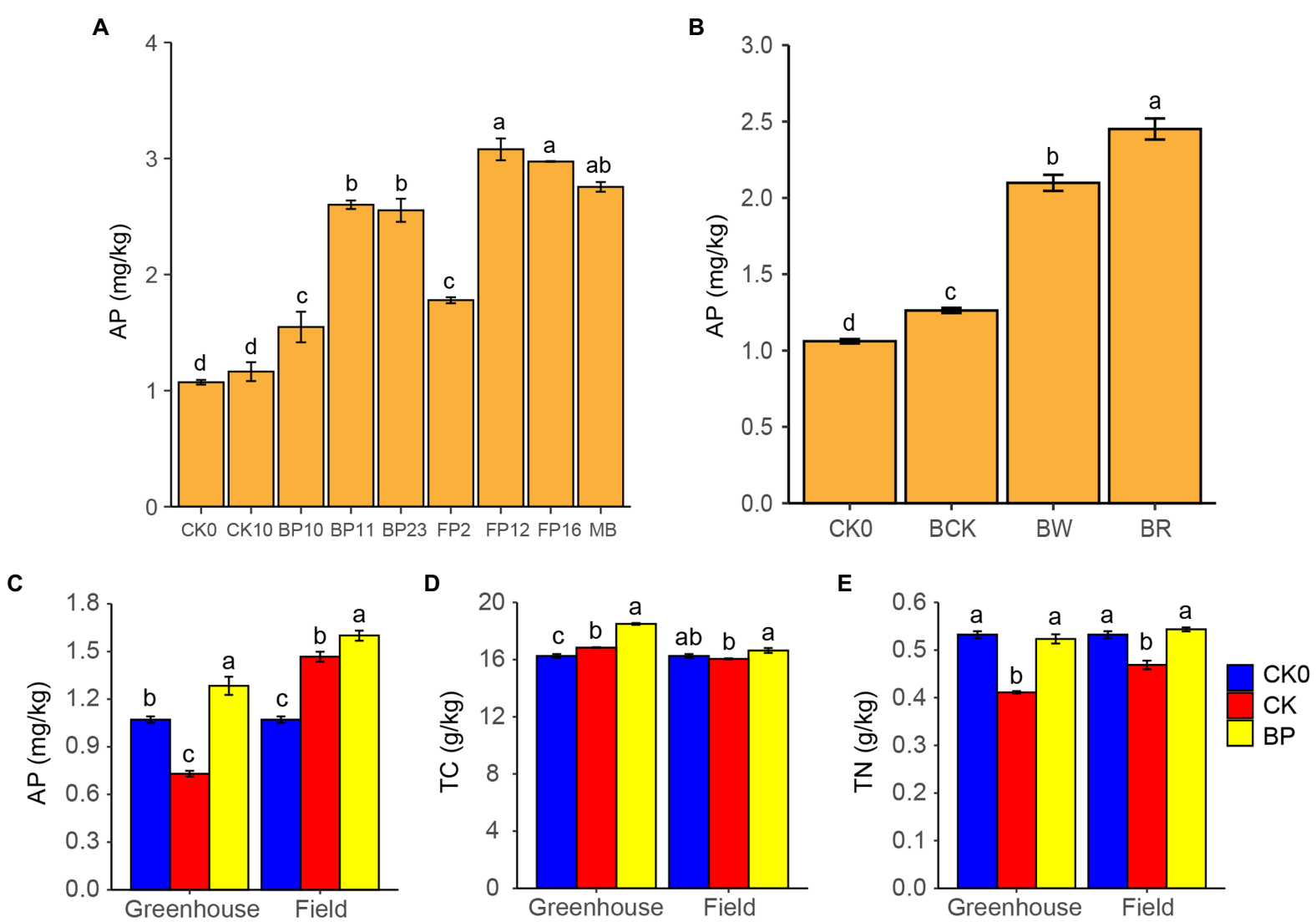

FIGURE 5 | Phosphate-solubilizing bacteria application potential. (A) AP in the barren rocky soil after treatment by phosphate-solubilizing bacteria, CK0, control group 0 day; CK10, control group 10 days; MB, mixed phosphate-solubilizing bacteria. (B) Effect of sweetpotato root exudates on phosphate-solubilizing, CK0, control group 0 day; BCK, control group without mixed phosphate-solubilizing bacteria 10 days; BW, mixed phosphate-solubilizing bacteria with sterile water; BR, mixed phosphate-solubilizing bacteria with sweetpotato root exudates. (C-E) Soil properties in greenhouse and field pot experiments, AP, available phosphorus; TC, total carbon; TN, total nitrogen; CKO group, control group 0 day; CK group, control group without phosphate-solubilizing bacteria 100 days; and BP group, mixed phosphate-solubilizing bacteria was applied 100 days. Different letters denote significant difference from a Tukey's HSD test ( $p<0.05)$.

\section{Greenhouse and Field Pot Experiments}

The application of PSB significantly increased the AP in the barren rocky soil. In the greenhouse and field pot experiment, AP in the barren rocky soil increased significantly from 1.07 to $1.28 \mathrm{mg} / \mathrm{kg}$ and $1.63 \mathrm{mg} / \mathrm{kg}$ in the BP group, respectively, which was both significantly higher than those $(0.73$ and $1.47 \mathrm{mg} / \mathrm{kg}$ ) in the CK group $(p<0.05$; Figure $5 \mathrm{C})$. In addition, if the $\mathrm{P}$ absorbed by sweetpotato is taken into account $(4.52$ and $7.10 \mathrm{mg} \mathrm{P}$ per sweetpotato in the greenhouse and field pot experiment, respectively), the PSB actually releases more P.

The application of PSB also affected the barren rocky soil properties such as $\mathrm{pH}, \mathrm{TC}$, and TN. Applying PSB decreased the $\mathrm{pH}$ of the barren rocky soil, which is beneficial to reduce alkalization of barren rocky soil. Meanwhile, applying PSB increased the TC and TN of barren rocky soil (Figures 5D,E).

Applying PSB increased the tuberous roots and vines yields, as well as $\mathrm{N}, \mathrm{P}$, and $\mathrm{K}$ content in sweetpotato. In the greenhouse and field pot experiment, the yields of tuberous roots of sweetpotato were 26.08 and $36.43 \mathrm{~g}$ in the BP group, respectively, which were significantly higher than those (16.21 and $29.38 \mathrm{~g}$ ) in the CK group $(p<0.05)$. Meanwhile, applying PSB increased the ratio of tuberous roots to total biomass of sweetpotato. Moreover, applying PSB even significantly increased the $\mathrm{N}, \mathrm{P}$, and $\mathrm{K}$ content in the sweetpotato roots and vines (Table 1; Supplementary Figure S5).

\section{DISCUSSION}

Our previous study found that sweetpotato grew well in AP-deficient rocky soil, and some PSB may be present in the sweetpotato rhizosphere (Ding et al., 2020). In this study, we screened six highly efficient PSB from sweetpotato rhizosphere rocky soil. Among them, $O$. haematophilum FP12 showed the highest P-solubilizing ability of $1,085.00 \mathrm{mg} / \mathrm{L}$ at 7 days. To our knowledge, it showed higher P-solubilizing ability than most of previously reported PSB (Chen et al., 2006; Sarikhani et al., 2019; Kaur and Kaur, 2020).

\section{Multi-Omics Reveal the Highly Efficient P-Solubilizing Mechanism of PSB FP12}

Organic acid secretion is an important P-solubilizing way in PSB (Zeng et al., 2016). We found that the concentrations of 
TABLE 1 | Physiological data of sweetpotato in greenhouse and field pot experiments.

\begin{tabular}{|c|c|c|c|c|c|c|c|c|c|c|}
\hline & & \multirow{2}{*}{$\begin{array}{l}\text { Tuberous } \\
\text { roots (g) }\end{array}$} & \multirow{2}{*}{$\begin{array}{l}\text { Fibrous } \\
\text { roots }(g)\end{array}$} & \multirow[t]{2}{*}{ Vines (g) } & \multicolumn{3}{|c|}{ Roots (g/kg) } & \multicolumn{3}{|c|}{ Vines (g/kg) } \\
\hline & & & & & $\mathbf{N}$ & $\mathbf{P}$ & $\mathbf{K}$ & $\mathbf{N}$ & $\mathbf{P}$ & $\mathbf{K}$ \\
\hline \multirow{2}{*}{$\begin{array}{l}\text { Greenhouse } \\
\text { pot }\end{array}$} & CK & $16.21 \pm 5.95$ & $2.78 \pm 0.98$ & $14.26 \pm 4.02$ & $4.65 \pm 0.02$ & $0.31 \pm 0.01$ & $15.30 \pm 0.01$ & $8.84 \pm 0.01$ & $0.57 \pm 0.00$ & $17.64 \pm 0.02$ \\
\hline & $\mathrm{BP}$ & $26.08 \pm 4.45^{*}$ & $3.93 \pm 1.94$ & $17.89 \pm 3.37$ & $7.41 \pm 0.00^{*}$ & $0.38 \pm 0.00^{*}$ & $16.05 \pm 0.03^{*}$ & $12.84 \pm 0.01^{*}$ & $0.61 \pm 0.00^{*}$ & $18.74 \pm 0.01^{*}$ \\
\hline \multirow[t]{2}{*}{ Field pot } & CK & $29.38 \pm 6.23$ & $11.37 \pm 2.68$ & $26.88 \pm 6.51$ & $4.97 \pm 0.01$ & $0.54 \pm 0.00$ & $16.57 \pm 0.01$ & $7.83 \pm 0.01$ & $0.61 \pm 0.00$ & $17.40 \pm 0.01$ \\
\hline & $\mathrm{BP}$ & $36.43 \pm 4.76^{*}$ & $10.58 \pm 5.02$ & $31.25 \pm 6.94$ & $7.54 \pm 0.01^{*}$ & $0.57 \pm 0.00^{*}$ & $16.91 \pm 0.01^{*}$ & $11.36 \pm 0.02^{*}$ & $0.63 \pm 0.00$ & $17.91 \pm 0.03^{*}$ \\
\hline
\end{tabular}

CK group, control group without phosphate-solubilizing bacteria 100 days; BP group, mixed phosphate-solubilizing bacteria was applied 100 days. ${ }^{*} p<0.05$.

organic acids in the IPM group were generally higher than those in the APM group, especially gluconic acid and malic acid, whose concentrations in the IPM group were 1.29-2.00 times higher than those in the APM group (Figure 2). These results may explain why the $\mathrm{pH}$ of the IPM group was lower than that of the APM group (Figure 1A). Thus, AP-deficiency could promote the secretion of organic acid by PSB, while AP inhibited it. This result is consistent with the previous finding (Zeng et al., 2017).

Direct oxidation of glucose to gluconic acid is thought to be the main P-solubilizing way in Gram-negative bacteria (Sashidhar and Podile, 2010; Luduena et al., 2018). We found that gluconic acid was the most prevalent organic acid in the media (Figure 2), which plays a major role in the rapid P-solubilization by PSB FP12. Whereas, a study in the PSB Burkholderia multivorans WS-FJ9 found that pyruvate was the main organic acid secreted when solubilizing $\mathrm{P}$ (Zeng et al., 2017). Another study in the PSB Enterobacter cloacae RW8 found that lactic acid, succinic acid, and citric acid were the main organic acids secreted (Li et al., 2017). These results showed that different PSB would secrete the varied types and concentrations of organic acids to solubilize P.

The genome contains the genetic information that allows bacteria to function. Genes related to various organic acid synthesis, acid shock regulatory proteins (RpoS, OmpR, PhoP, and Fur), acid/ alkaline phosphatase, IAA synthesis, and siderophores biosynthesis were identified in the PSB FP12 genome (Figure 3). The acid/ alkaline phosphatase suggested that PSB FP12 may degrade organic P. And the IAA synthesis and siderophores biosynthesis genes suggested that PSB FP12 may promote plant growth through producing IAA and siderophores, in addition to solubilizing $\mathrm{P}$ (Luduena et al., 2018).

A previous study has illustrated the important role of gluconic acid synthesis in P-solubilizing (Farhat et al., 2013). In our study, the expression of the GDH genes in the IPM group were higher than that in the APM group (Figure 4), which may result to the higher gluconic acid concentration in the IPM group (Figure 2). Our results differ from those in $B$. multivorans WS-FJ9, whose expression of gluconic acid synthesis genes are not affected by P availability (Zeng et al., 2017). This difference may be due to the different P-solubilizing mechanisms among PSB strains. For example, the PSB $B$. multivorans WS-FJ9 mainly secreted pyruvate to solubilize $\mathrm{P}$, not gluconic acid (Zeng et al., 2017).
The TCA cycle produces a variety of organic acids, such as citric acid, $\alpha$-ketoglutaric acid, succinic acid, and malic acid (Akram, 2014; Vuoristo et al., 2016). Transcriptome analysis revealed that the expression of genes related to the TCA cycle in the IPM group was generally higher than that in the APM group, excepting the MDH gene (Figure 4). MDH catalyzes malic acid to oxaloacetate (Sutherland and McAlisterhenn, 1985). Thus, low expression of $\mathrm{MDH}$ gene may be the reason why malic acid concentration in the IPM group was higher than that in the APM group (Figure 2). Pyruvate can be converted to organic acids such as acetic acid and lactic acid through the pyruvate metabolic pathway (Melo et al., 2018). Transcriptome analysis revealed that the expression of related genes (POX, LDH) was higher than that in the APM group (Figure 4), which might induce the higher acetic acid and lactic acid concentration in the IPM group (Figure 2).

Bacteria induce an acid tolerance response by producing acid shock proteins and changing cell membrane fluidity. Regulatory proteins such as RpoS, OmpR, PhoP, and Fur can affect the production of acid shock proteins (Hall and Foster, 1996). In addition, RpoS reduces cell membrane fluidity (Spector and Kenyon, 2012), and OmpR directly affects the outer membrane porin $\mathrm{OmpC}$ and $\mathrm{OmpF}$ to respond to external acids (Csonka and Hanson, 1991). We found that the expression levels of these regulatory proteins in the IPM group were significantly higher than those in the APM group $(p<0.05$; Figure 4). These results indicated that PSB FP12 enhanced its acid tolerance response in the IPM group, which helped it survive in an acidic environment.

Therefore, in an AP-deficient environment, PSB FP12 upregulated the expression of genes in the organic acid synthesis pathway and secreted more organic acids such as gluconic acid, malic acid, and acetic acid (Figures 2, 4). The expression patterns of related genes and the secretion of organic acids in PSB FP12 were different from some of those previously reported PSB, indicating that different PSB have various P-solubilizing mechanisms.

\section{The Screened PSB Significantly Increased the AP in the Barren Rocky Soil From the Laboratory to the Field}

The application of PSB is affected by many factors, such as soil properties, rhizosphere colonization, and the local climate (Gyaneshwar et al., 2002). A previous study found that P-solubilizing 
microorganisms did not play a direct role in supplementing soil AP for plants in about $70 \%$ of the experiments (Gyaneshwar et al., 2002). Therefore, we further studied the application effect of PSB through experiments such as treating the barren rocky soil with PSB and adding sweetpotato root exudates, as well as greenhouse potting and field potting (Supplementary Table S7). The barren rocky soil experiment indicated that all of these screened PSB had P-solubilizing effects on the barren rocky soil. Considering that the composite strains have stronger adaptability to complex environments, mixed PSB was used for further experiments (Scheuerl et al., 2020).

We found that adding sweetpotato root exudates improved the P-solubilizing effect of the PSB (Figure 5B). Plant root exudates are important sources of nutrients such as carbon and $\mathrm{N}$ for rhizosphere microorganisms, and plants can also affect the colonization of rhizosphere microorganisms through root exudates (Sasse et al., 2018). The sweetpotato root exudates might increase the P-solubilizing effect through promoting the colonization of PSB.

The results of the greenhouse and field pot experiments were consistent. The application of PSB increased the AP, TC, and $\mathrm{TN}$ in the barren rocky soil (Figures $5 \mathrm{C}-\mathbf{E}$ ). And the P-solubilizing effect of PSB was higher than that of most of previously reported PSB (Zhu et al., 2018). In addition, based on the preliminary $16 \mathrm{~S}$ rRNA sequencing results of our follow-up field experiment, the relative abundance of the PSB could be more than $1 \%$, which was significantly higher than that of the control (unpublished data). Moreover, $\mathrm{P}$ is an essential macro element required for plants, which is especially important for early stage root development, stem strength, and yield (Satyaprakash et al., 2017). In this study, the application of PSB increased the yield of sweetpotato tuberous roots, biomass and the ratio of tuberous roots to total biomass, and the content of $\mathrm{N}, \mathrm{P}$, and $\mathrm{K}$ in the roots and vines (Table 1 ). These results indicated that in the greenhouse and field environments, the PSB could improve the barren rocky soil fertility and promote sweetpotato growth. In adition, some PSB also showed a good growth-promoting effect on a variety of crops, such as $O$. haematophilum could promote the growth of corn and tobacco (Pereira and Castro, 2014; Gao et al., 2016). It would be an interesting and valuable work to study the effect of these screened PSB, especially the FP12, on other crops in future.

Chemical phosphate fertilizers applied to the barren rocky soil is easy to be washed away and cause serious environmental pollution (Huang et al., 2017). In addition, our preliminary research found that commercialized PSB did not work well in the barren rocky soil. Here, the screened PSB can effectively solubilize $\mathrm{P}$ and continuously alleviate the AP-deficiency in the barren rocky soil, showing great potential in reducing the application of chemical phosphate fertilizer and the related environmental pollution. Therefore, to pave the way toward their actual application in the rocky soil, more efficient PSB would be screened and the possible interaction among these screened PSB would be studied in future. More importantly, the biosafety potential of those screened PSB, especially the O. haematophilum FP12, would also be carefully and thoroughly analyzed before promoting their large-scale applications in the rocky soil.

\section{CONCLUSION}

We screened six strains of PSB from sweetpotato rhizosphere rocky soil. Among them, the PSB O. haematophilum FP12 had the best P-solubilizing ability, reaching $1,085.00 \mathrm{mg} / \mathrm{L}$ at 7 days. The assembled genome of PSB FP12 was $4.92 \mathrm{Mb}$ in length, containing 4,714 genes, including P-solubilizing and plant growth-promoting genes. In AP-deficient environment, PSB FP12 upregulated the expression of organic acid synthesis genes and produced more organic acids, leading to P-solubilization. Moreover, these PSB improved the barren rocky soil fertility and promoted sweetpotato yield in the laboratory and field experiments. This study provides efficient and adaptable PSB strains for barren rocky soil, which will reduce the environmental pollution caused by excessive chemical phosphate fertilizer and promote the environment-friendly agricultural development.

\section{DATA AVAILABILITY STATEMENT}

The datasets presented in this study can be found in online repositories. The names of the repository/repositories and accession number(s) can be found at: https://www.ncbi.nlm. nih.gov/, PRJNA662158, PRJNA662170, and MW454804-MW454809.

\section{AUTHOR CONTRIBUTIONS}

YD: conceptualization, methodology, data curation, software, writing - original draft, and writing - review and editing. ZY: methodology, data curation, formal analysis, and writing - review and editing. YF: investigation and data curation. $\mathrm{SH}$ and YL: investigation. $\mathrm{KH}$ : resources and writing - review and editing. HZ: writing - review and editing and funding acquisition. YJ: writing - review and editing, supervision, project administration, and funding acquisition. All authors contributed to the article and approved the submitted version.

\section{FUNDING}

This study was supported by the China Agriculture Research System of MOF and MARA (CARS-10-B24), the National Key R\&D Program of China (2018YFF0213505), the National Natural Science Foundation of China (31770395), the Science \& Technology Program of Sichuan Province (2017HH0077), and Innovation Academy for Seed Design, CAS.

\section{SUPPLEMENTARY MATERIAL}

The Supplementary Material for this article can be found online at: https://www.frontiersin.org/articles/10.3389/fmicb.2021.761972/ full\#supplementary-material 


\section{REFERENCES}

Akram, M. (2014). Citric acid cycle and role of its intermediates in metabolism. Cell Biochem. Biophys. 68, 475-478. doi: 10.1007/s12013-013-9750-1

Alikhan, N.-F., Petty, N. K., Zakour, N. L. B., and Beatson, S. A. (2011). BLAST ring image generator (BRIG): simple prokaryote genome comparisons. BMC Genomics 12:402. doi: 10.1186/1471-2164-12-402

Anders, S., Pyl, P. T., and Huber, W. (2015). HTSeq-a python framework to work with high-throughput sequencing data. Bioinformatics 31, 166-169. doi: 10.1093/bioinformatics/btu638

Balemi, T., and Negisho, K. (2012). Management of soil phosphorus and plant adaptation mechanisms to phosphorus stress for sustainable crop production: a review. J. Soil Sci. Plant Nutr. 12, 547-561. doi: 10.4067/ s0718-95162012005000015

Besemer, J., Lomsadze, A., and Borodovsky, M. (2001). GeneMarkS: a selftraining method for prediction of gene starts in microbial genomes. Implications for finding sequence motifs in regulatory regions. Nucleic Acids Res. 29, 2607-2618. doi: 10.1093/nar/29.12.2607

Bi, Q.-F., Li, K.-J., Zheng, B.-X., Liu, X.-P., Li, H.-Z., Jin, B.-J., et al. (2020). Partial replacement of inorganic phosphorus $(\mathrm{P})$ by organic manure reshapes phosphate mobilizing bacterial community and promotes $\mathrm{P}$ bioavailability in a paddy soil. Sci. Total Environ. 703:134977. doi: 10.1016/j. scitotenv.2019.134977

Buchfink, B., Xie, C., and Huson, D. H. (2015). Fast and sensitive protein alignment using DIAMOND. Nat. Methods 12, 59-60. doi: 10.1038/nmeth.3176

Chen, Y. L., Lee, C. C., Lin, Y. L., Yin, K. M., Ho, C. L., and Liu, T. (2015). Obtaining long 16S rDNA sequences using multiple primers and its application on dioxin-containing samples. BMC Bioinformatics 16:S13. doi: 10.1186/1471-2105-16-s18-s13

Chen, Y. P., Rekha, P. D., Arun, A. B., Shen, F. T., Lai, W. A., and Young, C. C. (2006). Phosphate solubilizing bacteria from subtropical soil and their tricalcium phosphate solubilizing abilities. Appl. Soil Ecol. 34, 33-41. doi: 10.1016/j.apsoil.2005.12.002

Csonka, L. N., and Hanson, A. D. (1991). Prokaryotic osmoregulation: genetics and physiology. Annu. Rev. Microbiol. 45, 569-606. doi: 10.1146/annurev. mi.45.100191.003033

Ding, Y., Jin, Y., He, K., Yi, Z., Tan, L., Liu, L., et al. (2020). Low nitrogen fertilization alter rhizosphere microorganism community and improve sweetpotato yield in a nitrogen-deficient rocky soil. Front. Microbiol. 11:678. doi: $10.3389 /$ fmicb. 2020.00678

Elhaissoufi, W., Ghoulam, C., Barakat, A., Zeroual, Y., and Bargaz, A. (2021). Phosphate bacterial solubilization: a key rhizosphere driving force enabling higher $\mathrm{P}$ use efficiency and crop productivity. J. Adv. Res. doi: 10.1016/j. jare.2021.08.014

Farhat, M. B., Fourati, A., and Chouayekh, H. (2013). Coexpression of the pyrroloquinoline quinone and glucose dehydrogenase genes from Serratia marcescens CTM 50650 conferred high mineral phosphate-solubilizing ability to Escherichia coli. Appl. Biochem. Biotechnol. 170, 1738-1750. doi: 10.1007/ s12010-013-0305-0

Gao, L., Kong, F., Feng, C., Wang, J., Gao, J., Shen, G., et al. (2016). Isolation, characterization, and growth promotion of phosphate-solubilizing bacteria associated with Nicotiana tabacum (Tobacco). Pol. J. Environ. Stud. 25, 993-1003. doi: 10.15244/pjoes/61820

Granada, C. E., Passaglia, L. M. P., de Souza, E. M., and Sperotto, R. A. (2018). Is phosphate solubilization the forgotten child of plant growthpromoting rhizobacteria? Front. Microbiol. 9:2054. doi: 10.3389/ fmicb.2018.02054

Gyaneshwar, P., Kumar, G. N., Parekh, L. J., and Poole, P. S. (2002). Role of soil microorganisms in improving $\mathrm{P}$ nutrition of plants. Plant Soil 245, 83-93. doi: 10.1023/A:1020663916259

Hall, H. K., and Foster, J. W. (1996). The role of fur in the acid tolerance response of Salmonella typhimurium is physiologically and genetically separable from its role in iron acquisition. J. Bacteriol. 178, 5683-5691. doi: 10.1128/ jb.178.19.5683-5691.1996

Huang, J., Xu, C.-C., Ridoutt, B. G., Wang, X.-C., and Ren, P.-A. (2017). Nitrogen and phosphorus losses and eutrophication potential associated with fertilizer application to cropland in China. J. Clean. Prod. 159, 171-179. doi: $10.1016 /$ j.jclepro.2017.05.008
Kaur, R., and Kaur, S. (2020). Variation in the phosphate solubilizing bacteria from virgin and the agricultural soils of Punjab. Curr. Microbiol. 77, 2118-2127. doi: 10.1007/s00284-020-02080-6

Kim, D., Langmead, B., and Salzberg, S. L. (2015). HISAT: a fast spliced aligner with low memory requirements. Nat. Methods 12, 357-360. doi: 10.1038/nmeth.3317

Langmead, B., and Salzberg, S. L. (2012). Fast gapped-read alignment with bowtie 2. Nat. Methods 9, 357-359. doi: 10.1038/nmeth.1923

Li, X., Wang, X., Chen, X., Cai, L., Zeng, Q., Shu, J., et al. (2017). Transcriptome profiling analysis of the phosphate-solubilizing mechanism of the white clover rhizosphere strain RW8. Acta Pratacul. Sin. 26, 168-179. doi: 10.11686/ cyxb2016399

Li, H., Yao, T., Zhang, R., Zhang, J., Li, Z., Rong, L., et al. (2019). Isolation and screening of phosphate-solubilizing bacteria from the rhizosphere of Trifolium pratense and culture medium optimization. Acta Pratacul. Sin. 28, 170-179. doi: 10.11686/cyxb2018064

Luduena, L. M., Anzuay, M. S., Angelini, J. G., McIntosh, M., Becker, A., Rupp, O., et al. (2018). Strain Serratia sp. S119: a potential biofertilizer for peanut and maize and a model bacterium to study phosphate solubilization mechanisms. Appl. Soil Ecol. 126, 107-112. doi: 10.1016/j.apsoil.2017.12.024

Luo, R. B., Liu, B. H., Xie, Y. L., Li, Z. Y., Huang, W. H., Yuan, J. Y., et al. (2012). SOAPdenovo2: an empirically improved memory-efficient short-read de novo assembler. Gigascience 1:18. doi: 10.1186/2047-217x-1-18

Manning, D. A. C., and Theodoro, S. H. (2018). Enabling food security through use of local rocks and minerals. Extract. Indus. Soc. 7, 480-487. doi: 10.1016/j. exis.2018.11.002

Melo, N., Mulder, K. C., Nicola, A. M., Carvalho, L. S., Menino, G. S., Mulinari, E., et al. (2018). Effect of pyruvate decarboxylase knockout on product distribution using Pichia pastoris (Komagataella phaffii) engineered for lactic acid production. Bioengineering 5:17. doi: 10.3390/ bioengineering 5010017

Murphy, J., and Riley, J. P. (1962). A modified single solution method for the determination of phosphate in natural waters. Anal. Chim. Acta 27, 31-36. doi: 10.1016/S0003-2670(00)88444-5

Natarajan, V. P., Zhang, X., Morono, Y., Inagaki, F., and Wang, F. (2016). A modified SDS-based DNA extraction method for high quality environmental DNA from seafloor environments. Front. Microbiol. 7:986. doi: 10.3389/ fmicb.2016.00986

Parastesh, F., Alikhani, H. A., and Etesami, H. (2019). Vermicompost enriched with phosphate-solubilizing bacteria provides plant with enough phosphorus in a sequential cropping under calcareous soil conditions. J. Clean. Prod. 221, 27-37. doi: 10.1016/j.jclepro.2019.02.234

Park, H. J., Kim, S. U., Jung, K. Y., Lee, S., Choi, Y. D., Owens, V. N., et al. (2021). Cadmium phytoavailability from 1976 through 2016: changes in soil amended with phosphate fertilizer and compost. Sci. Total Environ. 762:143132. doi: 10.1016/j.scitotenv.2020.143132

Pereira, S. I., and Castro, P. M. (2014). Diversity and characterization of culturable bacterial endophytes from Zea mays and their potential as plant growthpromoting agents in metal-degraded soils. Environ. Sci. Pollut. Res. Int. 21, 14110-14123. doi: 10.1007/s11356-014-3309-6

Rio, D. C., Ares, M., Hannon, G. J., and Nilsen, T. W. (2010). Purification of RNA using TRIzol (TRI reagent). Cold Spring Harb. Protoc. 2010:pdb.prot5439. doi: $10.1101 /$ pdb.prot5439

Roberts, T. L., and Johnston, A. E. (2015). Phosphorus use efficiency and management in agriculture. Resour. Conserv. Recycl. 105, 275-281. doi: 10.1016/j.resconrec.2015.09.013

Robinson, M. D., McCarthy, D. J., and Smyth, G. K. (2009). edgeR: a bioconductor package for differential expression analysis of digital gene expression data. Bioinformatics 26, 139-140. doi: 10.1093/bioinformatics/btp616

Sanders, E. R. (2012). Aseptic laboratory techniques: plating methods. J. Vis. Exp. 63:e3064. doi: 10.3791/3064

Sarikhani, M. R., Khoshru, B., and Greiner, R. (2019). Isolation and identification of temperature tolerant phosphate solubilizing bacteria as a potential microbial fertilizer. World J. Microbiol. Biotechnol. 35:126. doi: 10.1007/s11274-019-2702-1

Sashidhar, B., and Podile, A. R. (2010). Mineral phosphate solubilization by rhizosphere bacteria and scope for manipulation of the direct oxidation pathway involving glucose dehydrogenase. J. Appl. Microbiol. 109, 1-12. doi: 10.1111/j.1365-2672.2009.04654.x 
Sasse, J., Martinoia, E., and Northen, T. (2018). Feed your friends: do plant exudates shape the root microbiome? Trends Plant Sci. 23, 25-41. doi: 10.1016/j.tplants.2017.09.003

Satyaprakash, M., Nikitha, T., Reddi, E., Sadhana, B., and Vani, S. S. (2017). Phosphorous and phosphate solubilising bacteria and their role in plant nutrition. Int. J. Curr. Microbiol. App. Sci. 6, 2133-2144. doi: 10.20546/ ijcmas.2017.604.251

Scheuerl, T., Hopkins, M., Nowell, R. W., Rivett, D. W., Barraclough, T. G., and Bell, T. (2020). Bacterial adaptation is constrained in complex communities. Nat. Commun. 11:754. doi: 10.1038/s41467-020-14570-Z

Spector, M. P., and Kenyon, W. J. (2012). Resistance and survival strategies of Salmonella enterica to environmental stresses. Food Res. Int. 45, 455-481. doi: 10.1016/j.foodres.2011.06.056

Sutherland, P., and McAlisterhenn, L. (1985). Isolation and expression of the Escherichia coli gene encoding malate dehydrogenase. J. Bacteriol. 163, 1074-1079. doi: 10.1128/jb.163.3.1074-1079.1985

van Hees, P. A. W., Dahlén, J., Lundström, U. S., Borén, H., and Allard, B. (1999). Determination of low molecular weight organic acids in soil solution by HPLC. Talanta 48, 173-179. doi: 10.1016/S0039-9140(98)00236-7

Vuoristo, K. S., Mars, A. E., Sanders, J. P. M., Eggink, G., and Weusthuis, R. A. (2016). Metabolic engineering of TCA cycle for production of chemicals. Trends Biotechnol. 34, 191-197. doi: 10.1016/j.tibtech.2015.11.002

Wei, Y., Zhao, Y., Lu, Q., Cao, Z., and Wei, Z. (2018). Organophosphorusdegrading bacterial community during composting from different sources and their roles in phosphorus transformation. Bioresour. Technol. 264, 277-284. doi: 10.1016/j.biortech.2018.05.088

Wilkinson, B. H., McElroy, B. J., Kesler, S. E., Peters, S. E., and Rothman, E. D. (2009). Global geologic maps are tectonic speedometers-rates of rock cycling from area-age frequencies. Geol. Soc. Am. Bull. 121, 760-779. doi: 10.1130/ B26457.1

Ye, J., Zhang, Y., Cui, H. H., Liu, J. W., Wu, Y. Q., Cheng, Y., et al. (2018). WEGO 2.0: a web tool for analyzing and plotting GO annotations, 2018 update. Nucleic Acids Res. 46, W71-W75. doi: 10.1093/nar/gky400

Yh, Y. (2014). Isolation and identification of phosphate-solubilizing microorganism from Soil. Henan Agricultural University.

Yoon, S.-H., Ha, S.-M., Kwon, S., Lim, J., Kim, Y., Seo, H., et al. (2017a). Introducing EzBioCloud: a taxonomically united database of 16S rRNA gene sequences and whole-genome assemblies. Int. J. Syst. Evol. Microbiol. 67, 1613-1617. doi: 10.1099/ijsem.0.001755
Yoon, S.-H., Ha, S.-M., Lim, J., Kwon, S., and Chun, J. (2017b). A large-scale evaluation of algorithms to calculate average nucleotide identity. Antonie Van Leeuwenhoek 110, 1281-1286. doi: 10.1007/s10482-017-0844-4

Yu, L. Y., Huang, H. B., Wang, X. H., Li, S., Feng, N. X., Zhao, H. M., et al. (2019). Novel phosphate-solubilising bacteria isolated from sewage sludge and the mechanism of phosphate solubilisation. Sci. Total Environ. 658, 474-484. doi: 10.1016/j.scitotenv.2018.12.166

Zeng, Q., Wu, X., Wang, J., and Ding, X. (2017). Phosphate solubilization and gene expression of phosphate-solubilizing bacterium Burkholderia multivorans WS-FJ9 under different levels of soluble phosphate. J. Microbiol. Biotechnol. 27, 844-855. doi: 10.4014/jmb.1611.11057

Zeng, Q., Wu, X., and Wen, X. (2016). Effects of soluble phosphate on phosphatesolubilizing characteristics and expression of GCD gene in Pseudomonas frederiksbergensis JW-SD2. Curr. Microbiol. 72, 198-206. doi: 10.1007/ s00284-015-0938-z

Zhu, J., Li, M., and Whelan, M. (2018). Phosphorus activators contribute to legacy phosphorus availability in agricultural soils: a review. Sci. Total Environ. 612, 522-537. doi: 10.1016/j.scitotenv.2017.08.095

Zitouni, H., Hssaini, L., Ouaabou, R., Viuda-Martos, M., Hernández, F., Ercisli, S., et al. (2020). Exploring antioxidant activity, organic acid, and phenolic composition in strawberry tree fruits (Arbutus unedo L.) growing in Morocco. Plants 9:1677. doi: 10.3390/plants9121677

Conflict of Interest: The authors declare that the research was conducted in the absence of any commercial or financial relationships that could be construed as a potential conflict of interest.

Publisher's Note: All claims expressed in this article are solely those of the authors and do not necessarily represent those of their affiliated organizations, or those of the publisher, the editors and the reviewers. Any product that may be evaluated in this article, or claim that may be made by its manufacturer, is not guaranteed or endorsed by the publisher.

Copyright (C) 2021 Ding, Yi, Fang, He, Li, He, Zhao and Jin. This is an open-access article distributed under the terms of the Creative Commons Attribution License (CC BY). The use, distribution or reproduction in other forums is permitted, provided the original author(s) and the copyright owner(s) are credited and that the original publication in this journal is cited, in accordance with accepted academic practice. No use, distribution or reproduction is permitted which does not comply with these terms. 


\section{Glossary}

$\begin{array}{ll}\text { AP } & \text { Available phosphorus } \\ \text { P } & \text { Phosphorus } \\ \text { PSB } & \text { Phosphate-solubilizing bacteria } \\ \text { TP } & \text { Total phosphorus } \\ \text { ANI } & \text { Average Nucleotide Identity } \\ \text { RPKM } & \text { Reads Per Kilobase per Million mapped reads } \\ \text { K } & \text { Potassium } \\ \text { N } & \text { Nitrogen } \\ \text { TC } & \text { Total carbon } \\ \text { TN } & \text { Total nitrogen } \\ \text { D/d } & \text { The ratio of the P-solubilizing circle to the diameter of the round hole } \\ \text { PQQ } & \text { Pyrroloquinoline quinone } \\ \text { IAA } & \text { Indole acetic acid } \\ \text { ALDH } & \text { Aldehyde dehydrogenase } \\ \text { GDH } & \text { Glucose dehydrogenase } \\ \text { CS } & \text { Citrate synthase } \\ \text { ACO } & \text { Aconitic hydratase } \\ \text { IDH } & \text { Isocitrate dehydrogenase } \\ \text { OGDH } & \alpha \text {-ketoglutarate dehydrogenase } \\ \text { SUC } & \text { Succinyl-CoA synthetase } \\ \text { SDH } & \text { Succinate dehydrogenase } \\ \text { FH } & \text { Fumarate hydratase } \\ \text { MDH } & \text { Malate dehydrogenase } \\ \text { POX } & \text { Pyruvate dehydrogenase } \\ \text { LDH } & \text { L-lactate dehydrogenase }\end{array}$

